\title{
Monocyte Chemoattractant Protein-1 and Its Receptor CCR-2 in Piglet Lungs Exposed to Inhaled Nitric Oxide and Hyperoxia
}

\author{
IKECHUKWU I. EKEKEZIE, DONALD W. THIBEAULT, ROBERT E. GAROLA, AND \\ WILLIAM E. TRUOG \\ Sections of Neonatology [I.I.E., D.W.T., W.E.T.] and Pathology [R.E.G.], Children's Mercy Hospitals and \\ Clinics, University of Missouri at Kansas City School of Medicine, Kansas City, \\ Missouri 64108-9883, U.S.A.
}

\begin{abstract}
ABST
Monocyte chemoattractant protein-1 (MCP-1), acting through
its C-C chemokine receptor 2 (CCR-2), has important roles in
inflammation, angiogenesis, and wound repair. The individual
and combined effects of inhaled nitric oxide (NO) and hyperoxia
on lung MCP-1 and CCR-2 in relation to lung leukocyte dynam-
ics are unknown. Because MCP-1 gene is up-regulated by oxi-
dants, we hypothesized that inhaled NO with hyperoxia will
increase MCP-1 production and CCR-2 expression more than
either gas alone. We randomly assigned young piglets to breathe
room air (RA), RA +50 ppm NO (RA + NO), $\mathrm{O}_{2}$, or $\mathrm{O}_{2}+\mathrm{NO}$ for
1 or 5 d before sacrifice. Lungs were lavaged and tissues
preserved for hybridization studies, Western blotting, histology,
and immunohistochemistry. The results show that lung MCP-1
production and alveolar macrophage count were significantly
elevated in the 5-d $\mathrm{O}_{2}$ and $\mathrm{O}_{2}+\mathrm{NO}$ groups relative to the RA
group ( $p \leq 0.05)$. In contrast, lung CCR-2 abundance was
diminished in the $\mathrm{O}_{2}$ group ( $\left.p \leq 0.05\right)$, but not in the $\mathrm{O}_{2}+\mathrm{NO}$
group, compared with the RA group. No difference was detected
\end{abstract}
Animals exposed to prolonged hyperoxia suffer lung injury from pulmonary sequestration of activated leukocytes, which release cytokines, reactive oxygen species, and tissuedegrading enzymes (1-3). The leukocyte influx is orchestrated and amplified by chemotactic factors (1-4).

In the early phase, neutrophil accumulation predominates, but this pattern changes to one of monocytes/macrophages beyond $72 \mathrm{~h} \mathrm{(3).} \mathrm{The} \mathrm{change} \mathrm{in} \mathrm{the} \mathrm{inflammatory} \mathrm{cell} \mathrm{compo-}$ sition results from proliferation of resident alveolar macrophages as well as pulmonary transmicrovascular migration of blood monocytes $(1,3)$. The factors controlling these later

Received February 19, 2001; accepted June 15, 2001.

Correspondence and reprint requests: Ikechukwu I. Ekekezie, M.D., Department of Neonatology, Children's Mercy Hospitals and Clinics, 2401 Gillham Road, Kansas City, MO 64108-9883, U.S.A.; e-mail: IEkekezie@cmh.edu

Supported in part by NIH R-01 HL62079 and by a Physician Scientist Award from Children's Mercy Hospitals and Clinics (W.E.T.) and Katherine B. Richardson Foundation (I.I.E. and D.W.T.). in any variable studied at $24 \mathrm{~h}$. CCR-2 distribution was similar in all groups with staining of alveolar septa, macrophages, vascular endothelium, and the luminal epithelial surface of airways. We conclude that although hyperoxia increases MCP-1 in young piglet lungs, it also decreases CCR-2 abundance, which may limit participation of MCP-1 in alveolar macrophage recruitment. Inhaled NO, unlike hyperoxia, has no significant independent effect, but its concurrent administration during hyperoxia attenuates the decremental effect of hyperoxia on CCR-2 abundance.

(Pediatr Res 50: 633-640, 2001)

\section{Abbreviations}

MCP-1, monocyte chemoattractant protein-1

NO, nitric oxide

MPO, myeloperoxidase

CCR-2, C-C chemokine receptor 2

RA, room air

RPA, ribonuclease protection assay events are not fully understood, but known proinflammatory cytokines may be involved.

MCP-1 is a C-C chemokine with activating and chemoattractant actions on monocytes and macrophages (5). In addition to its chemoattractant characteristics, MCP-1 also induces mesothelial, fibroblast, endothelial, and vascular smooth muscle cell proliferation and migration (6-9). MCP-1 is produced by various immune and nonimmune cell types including alveolar macrophages (5).

The actions of MCP-1 are mediated primarily through CCR-2 (10). These receptors are now known to be expressed by mesothelial, fibroblasts, and endothelial cells, as well as vascular smooth muscle cells (6-9). CCR-2 are members of the $\mathrm{G}$ protein-linked, heptahelical transmembrane domain receptor family.

The chemoattractant actions of MCP-1 on monocytes and macrophages, like its other properties, derive from activation of CCR-2 receptors. The effect of hyperoxia on lung CCR-2 
expression is unknown. A recent study found that although MCP-1 production increased in newborn rabbit lungs in response to hyperoxia, there was no correlation between MCP-1 levels and alveolar macrophage recruitment into the lung (11). Determination of the effect of hyperoxia on lung CCR-2 may contribute to understanding the role of MCP-1 during hyperoxic lung injury.

The MCP-1 gene contains oxidant responsive elements, and increases in MCP-1 mRNA transcription in response to reactive oxygen species have been reported $(12,13)$. NO, a prooxidant gas with demonstrated antiinflammatory and vasoactive properties, is used often in conjunction with hyperoxia to treat neonatal pulmonary hypertension (14-16). High levels of oxidant-reactive nitrogen intermediaries are generated in the presence of NO and oxygen $(17,18)$. The effect of NO alone, or during concurrent exposure with hyperoxia, on lung MCP-1 production and CCR-2 distribution and abundance has not been examined.

Because the MCP-1 gene is transcriptionally up-regulated in the presence of oxidant elements (12), and because NO, like oxygen, is capable of generating oxidants (19), we hypothesized that concurrent exposure to inhaled $\mathrm{NO}$ and high inspired oxygen concentration will result in increased lung MCP-1 production more than exposure to either gas alone. Additionally, we hypothesized that lung CCR-2 will show a similar trend. We used a young piglet model (20) characterized by rapidly growing lungs to assess lung $\mathrm{MCP}-1$ production and CCR-2 and leukocyte dynamics after 1 and $5 \mathrm{~d}$ of separate or concurrent exposure to $\mathrm{NO}$ and hyperoxia.

\section{METHODS}

Animal exposure and sacrifice. Twenty-eight 10- to 14-dold piglets of both sexes were randomly assigned to four exposure groups to breathe, in a 200-L chamber for $5 \mathrm{~d}$, either 1) RA, 2) RA +50 ppm NO, 3) hyperoxia $\left(\mathrm{O}_{2}\right.$; inspired fraction of oxygen $\geq 0.96$ ), or 4) $\mathrm{O}_{2}+\mathrm{NO}$. Ten additional animals breathed $\mathrm{O}_{2}$ or $\mathrm{O}_{2}+50 \mathrm{ppm} \mathrm{NO}$ for $1 \mathrm{~d}$. Exposure was performed at ambient temperature with the animals allowed free access to food and water. Medical-grade oxygen and nitric oxide (Puritan Bennett, Overland Park, KS, U.S.A.) were routed by way of connectors and regulators to the inlet port of the exposure chamber. Humidified oxygen and nitric oxide were introduced at a flow rate sufficient to maintain chamber concentrations $\geq 96 \%$ and $50 \mathrm{ppm}$, respectively, throughout the experiment. Four $150 \mathrm{~g}$ soda lime canisters and 500-g activated charcoal canisters (Sigma Chemical Co., St. Louis, $\mathrm{MO}$, U.S.A.) were used to scavenge $\mathrm{CO}_{2}$ and $\mathrm{NO}_{2}$. Chamber outlet port gas concentration was monitored for oxygen (Hudson Medical, Temecula, CA, U.S.A.), $\mathrm{CO}_{2}$ (model ABL30 Blood Gas Analyzer, Radiometer, Westlake, OH, U.S.A.), and $\mathrm{NO}$ and $\mathrm{NO}_{2}$ (Sensor Stik, $\mathrm{NO}$ model 4584 and $\mathrm{NO}_{2}$ model 4586, Exidyne Instruments, Exton, PA, U.S.A.).

At the end of the exposure period, anesthesia was accomplished with $2 \mathrm{mg} / \mathrm{kg}$ xylazine, $20 \mathrm{mg} / \mathrm{kg}$ ketamine, and 40 $\mathrm{mg} / \mathrm{kg}$ sodium pentobarbital before sacrifice. Euthanasia was accomplished with high-dose pentobarbital. The lungs were removed promptly on cessation of cardiac activity. The right lung was lavaged with six aliquots of $25 \mathrm{~mL}$ of PBS, and the recovered lavage fluid was filtered to separate the cells, then stored at $-80^{\circ} \mathrm{C}$ until analyzed. Pieces from the unlavaged left lung were minced, then frozen in liquid nitrogen and stored at $-80^{\circ} \mathrm{C}$ until used for Western blot and hybridization studies. The remaining left lower lobe was fixed in $4 \%$ formalin and used for immunohistochemistry.

The study was approved by the Institutional Animal Care Utilization Committee of the University of Missouri at Kansas City, MO.

RPA for MCP-1 and IL-8 mRNA. Total RNA was isolated from lung tissue samples using Tri-Reagent (Sigma Chemical Co.). Multiprobe RPA was performed according to the manufacturer's protocol (BD PharMingen, San Diego, CA, U.S.A.). Briefly, $\left[{ }^{32} \mathrm{P}\right] \mathrm{UTP}-$ labeled antisense RNA probes were generated for IL-8, MCP-1, and the housekeeping genes L32 and glyceraldehyde-3-phosphate dehydrogenase by in vitro $\mathrm{T} 7$ polymerase-directed transcription from a mix of porcine partial cDNA templates. The synthesized probe set was diluted to a final concentration of $2 \times 10^{5} \mathrm{cpm} / \mu \mathrm{L}$. Two microliters of the diluted probe set was mixed and hybridized to $6 \mu \mathrm{g}$ of total lung RNA isolate in $8 \mu \mathrm{L}$ of hybridization buffer. The samples were then incubated for $16 \mathrm{~h}$ in a water bath prewarmed to $90^{\circ} \mathrm{C}$ but immediately decreased to $56^{\circ} \mathrm{C}$, allowing the temperature to ramp down slowly during this period. Unhybridized RNA, including probes, was then digested with RNase A and $\mathrm{T} 1$ for $60 \mathrm{~min}$ at $37^{\circ} \mathrm{C}$. This was followed by phenolchloroform-isoamyl alcohol extraction of the hybridized or protected RNA duplexes after treatment with proteinase $\mathrm{K}$. The hybridized RNA was then resolved on a 5\% acrylamide, $7 \mathrm{M}$ urea gel by electrophoresis, allowing for separation of protected or duplex RNA strands into discrete bands based on the graded lengths of the probe cDNA templates. Gels were dried under vacuum for about $1 \mathrm{~h}$ at $80^{\circ} \mathrm{C}$. Dry gels were then developed overnight at $-70^{\circ} \mathrm{C}$ on a film (Kodak X-AR, Eastman Kodak, Rochester, NY, U.S.A.) in a cassette equipped with an intensifying screen. For quantitation of mRNA, the band intensities of the autoradiograms were measured on a densitometer running Image Quant software (Molecular Dynamics, Sunnyvale, CA, U.S.A.). The MCP-1 and IL-8 data were then normalized to that of the housekeeping gene L32.

MCP-1 protein assay. Lung lavage fluid MCP-1 protein level was determined by a solid-phase sandwich ELISA, using a commercially available kit according to the manufacturer's instructions (BioSource International, Camarillo, CA, U.S.A.). Briefly, $100 \mu \mathrm{L}$ of standards and samples were added to wells in a microtiter plate followed by $100 \mu \mathrm{L}$ of antigen-specific biotin conjugate. The mixture was allowed to incubate for $2 \mathrm{~h}$, then wells were aspirated and washed four times with wash buffer. One hundred microliters of streptavidin-HRP conjugate was then added to each well, followed by incubation for $30 \mathrm{~min}$ at room temperature. After aspiration and washing four times with wash buffer, $100 \mu \mathrm{L}$ of stabilized chromogen was added to each well, followed by incubation in the dark for $30 \mathrm{~min}$. The reaction was stopped with $100 \mu \mathrm{L}$ of stop solution, and the absorbance was read from a microtiter plate optical reader at $450 \mathrm{~nm}$. The MCP-1 concentration in the samples was interpolated from the standard curve. 
Western blotting CCR-2. CCR-2 protein expression in the piglet lungs was analyzed by Western blot (BD Biosciences, Lexington, KY, U.S.A.). Briefly, after sample preparation, 35 $\mu \mathrm{g}$ per well of total lung protein extract was electrophoresed in a 13-well, $16 \mathrm{~cm} \times 16 \mathrm{~cm} \times 1 \mathrm{~mm}, 5-15 \%$ gradient SDS polyacrylamide gel. A lane containing molecular weight standards composed of an antibody cocktail was included. The gel was run overnight at constant milliamps, then transferred to Immobilon-P nylon membrane (Millipore Corp., Bedford, MA, U.S.A.) for $1 \mathrm{~h}$ at $1 \mathrm{~A}$. After transfer, the membrane was blocked for $1 \mathrm{~h}$ with $5 \%$ milk. Next, the membrane was clamped with Western blot manifold, which isolates 13 channels across the membrane. In each channel an antibody cocktail including CCR-2 (R \& D Systems, Minneapolis, MN, U.S.A.) and RACK-1 (Transduction Laboratories, Lexington, KY, U.S.A.) was added and allowed to hybridize for $1 \mathrm{~h}$. RACK-1 protein expression is stable and therefore was used as an internal control, and a human endothelial cell lysate was included as a CCR-2-positive control. The blot was removed from the manifold, washed, and hybridized for $30 \mathrm{~min}$ with goat anti-mouse horseradish peroxidase. The membrane was washed and developed with chemiluminescence (Super Signal West Pico, Pierce, Rockford IL, U.S.A.). CCR-2 and RACK-1 bands were digitized and mean CCR-2/RACK-1 ratios calculated.

Histology and immunohistochemistry. Formalin-fixed lung sections embedded in paraffin were cut $4 \mu \mathrm{m}$ thick and mounted on positively charged glass slides. After deparaffinization and rehydration with Tris-buffered saline, $\mathrm{pH}$ 7.6, endogenous peroxidase was quenched with hydrogen peroxide.

Myeloperoxidase. Lung neutrophil accumulation was assessed by immunohistochemical staining for the neutrophilspecific enzyme MPO. Briefly, sections were immunostained with rabbit polyclonal antiserum to human MPO (DAKO, Carpinteria, CA, U.S.A.) using a modified avidin-biotinperoxidase method (16). Sections were incubated with blocking serum (DAKO) for 10 min followed by primary antiserum overnight. After washing, sections were incubated with biotinylated IgG and stained with an immunoperoxidase technique according to the manufacturer's instructions (Vectastain $\mathrm{ABC}$ Elite Kit; Vector Laboratories, Burlingame, CA, U.S.A.). Antigenic sites were visualized by addition of the chromogen 3,3' diaminobenzidine. Slides were counterstained with light green SF yellowish (EM Diagnostic Systems, Inc., Gibbstown, NJ, U.S.A.). Negative control slides were stained using the same procedure, omitting the primary antibody or adding a nonimmune serum. The sections were visualized under light microscopy and semiquantitated by two blinded observers using a 1-4 scale. The scale was defined as 1 , no staining; 2 , few staining; 3 , moderate staining; and 4 , large and diffuse staining.

CCR-2 distribution. The immunohistochemical method for lung CCR-2 is similar to that described above for MPO, except that sections were immunostained with goat polyclonal antibody to CCR-2 (Research Diagnostics, Flanders, NJ, U.S.A.). The sections were visualized under light microscopy for tissue CCR-2 stain distribution.

Intraalveolar macrophages. Glass slides with hematoxylin and eosin-stained lung sections were made. The mean number of intraalveolar macrophages was obtained on light microscopy by counting the macrophages within $1 \mathrm{~mm}^{2}$ of 10 high-power fields/slide. The count was performed by a single pathologist blinded to the experimental groups. Macrophages were identified by their characteristic morphologic and cytologic appearance.

Statistics. Statistical analysis was performed using a computerized statistical software package, INSTAT (GraphPad Software, San Diego, CA, U.S.A.). Multiple comparisons for parametric data were made with one-way ANOVA and nonparametric data with Kruskal-Wallis test. Post hoc analysis with Tukey-Kramer or Student-Newman-Keuls to detect the differing pairs was performed when appropriate. A $p<0.05$ was considered significant. Results are expressed as mean \pm SD unless otherwise noted.

\section{RESULTS}

All animals survived. Evidence of respiratory distress developed in the 5- $\mathrm{d} \mathrm{O}_{2}$ and 5- $\mathrm{d}_{2}+\mathrm{NO}$ piglet groups, with variable levels of tachypnea and retractions. Animals in other groups and the 1-d exposure group did not exhibit respiratory distress.

MCP-1 and IL-8 $\boldsymbol{m R N A}$. Figure 1 is a photomicrograph of the bands from the experimental groups obtained from RPA for MCP-1 and IL-8 mRNA. As shown in Figures 2 and 3, significantly higher levels of MCP-1 and IL-8 mRNA were detected in the 5-d $\mathrm{O}_{2}$ and $\mathrm{O}_{2}+\mathrm{NO}$-exposed piglet lungs relative to the RA controls $(p<0.001$ and $p<0.01$, respectively). Mean MCP-1 and IL- 8 mRNA levels in the RA+NO groups were not different from the RA group.

MCP-1 protein assay. In the 5-d piglet exposure experiment, mean MCP-1 protein levels in the lavage fluid were significantly greater in the $\mathrm{O}_{2}$ and $\mathrm{O}_{2}+\mathrm{NO}$ groups compared with the RA group ( $p<0.01$ and 0.001 , respectively; Fig. 4). In addition, the $\mathrm{O}_{2}+\mathrm{NO}$ group had a statistically higher MCP-1

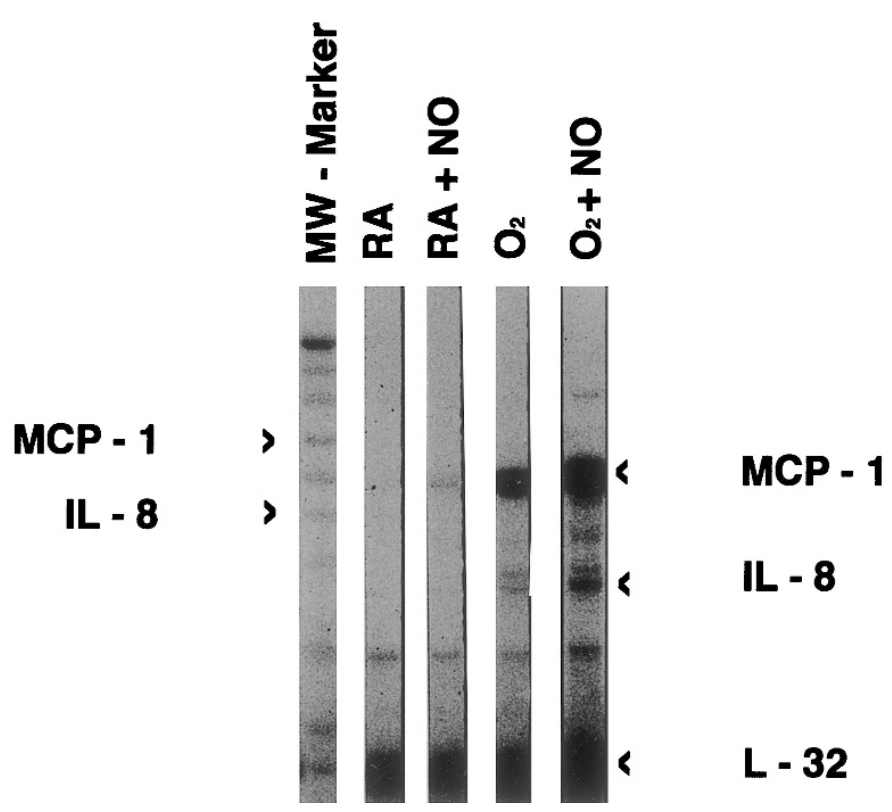

Figure 1. Photograph from autoradiogram of a multiprobe RPA for mRNA of chemokines and housekeeping genes showing representative lanes for the 5-d piglet experimental groups. Note the bands for MCP-1 and IL-8. The housekeeping gene L32 appeared relatively unchanged and, therefore, was used for normalization as reported in Figure 2. $M W$, molecular weight. 


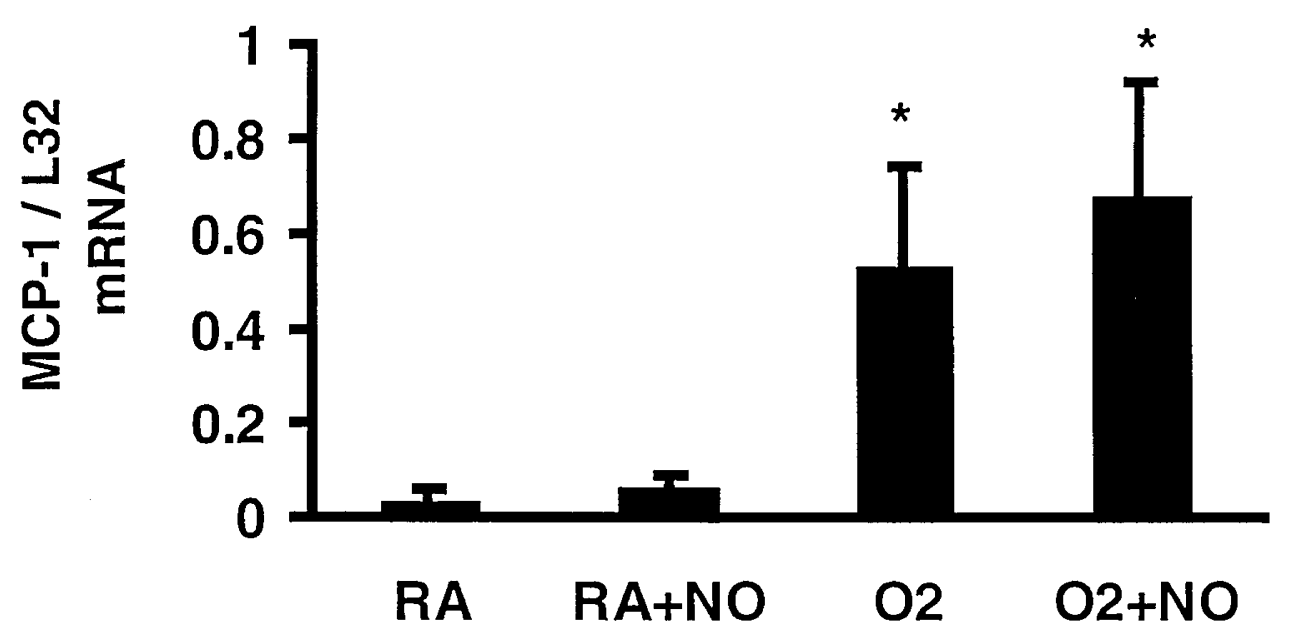

Figure 2. Graph of densitometric measurements for MCP-1 mRNA bands in the autoradiogram from the experimental groups, normalized to that of the housekeeping gene L32. Note the increased levels of MCP-1 mRNA in the $\mathrm{O}_{2}$ and $\mathrm{O}_{2}+\mathrm{NO}$ group. * $p<0.05$ compared with RA group.

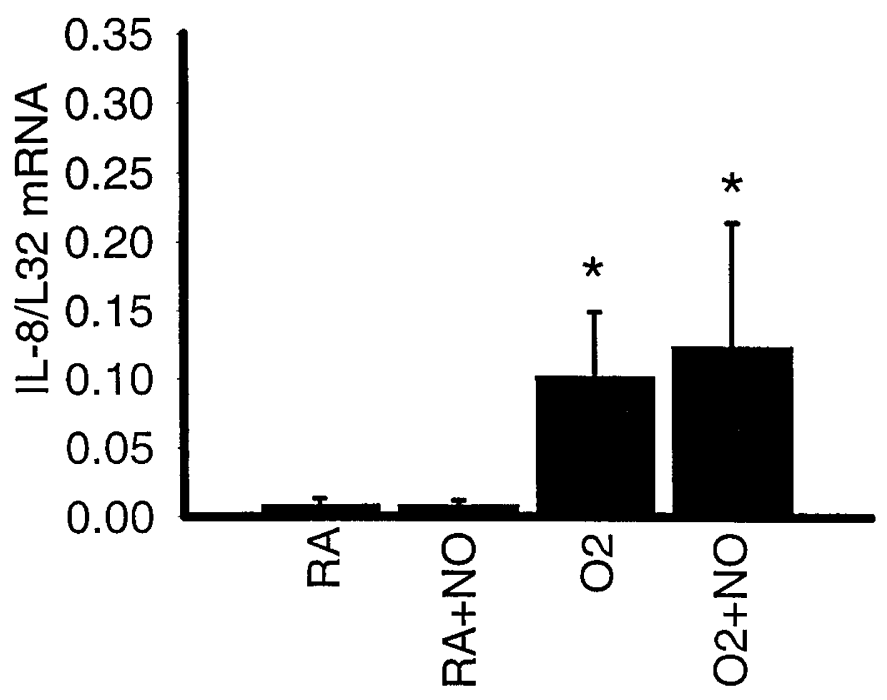

Figure 3. Graph of densitometric measurements for IL-8 mRNA bands in the autoradiogram from the experimental groups, normalized to that of the housekeeping gene L32. Note that IL-8 mRNA is increased in the $\mathrm{O}_{2}$ and $\mathrm{O}_{2}+\mathrm{NO}$ group. ${ }^{*} p<0.05$ compared with RA group.

level than the $\mathrm{O}_{2}$ group $(p<0.01)$. The mean MCP-1 level in the RA+NO group was not different from that of the RA group. MCP-1 levels were barely detectable in the 24-h experimental groups and were not different from the RA group.

Western blotting $\boldsymbol{C C R}-2$. Figure 5 shows the protein band detected with anti-CCR-2 after SDS-PAGE of protein extracts from the piglet lungs. The protein we detect is approximately $52 \mathrm{kD}$; this is $10 \mathrm{kD}$ larger than the predicted mobility on the basis of the amino acid sequence. The discrepancy is most likely caused by existence of the receptor in the glycosylated form (21). This same $52-\mathrm{kD}$ protein is detected in the human endothelial cells used as positive controls. Also previous Western blots in which we used CCR-2 alone showed this band as being specific for the CCR-2 MAb and not RACK-1 (36 kD). A graph of the mean CCR-2 protein values obtained for the different piglet groups is shown in Figure 6. The values are those of CCR-2 bands normalized to those of RACK-1 from the same lane as determined by densitometry. The mean
CCR-2 protein value from the RA+NO piglet lungs, although higher than that from the RA group lungs, showed no statistical difference when compared. However, the mean value from the $\mathrm{O}_{2}$, but not the $\mathrm{O}_{2}+\mathrm{NO}$, group lungs showed a significant decrease in comparison to that of the RA group lungs. Thus concurrent inhaled NO during exposure to hyperoxia prevented the decremental effect of hyperoxia on lung CCR-2 protein level.

Histology and immunohistochemistry. Histologically, there was increased interstitial leukocytic infiltrate, alveolar septal edema with focal alveolitis, and alveolar epithelial disruption in the $\mathrm{O}_{2}$ and $\mathrm{O}_{2}+\mathrm{NO}-$ exposed piglets. The histologic findings in the RA+NO group did not differ from the RA group.

CCR-2 distribution. The cellular and tissue distribution of CCR-2 in the piglet lungs was determined by examining immunohistochemically prepared slides of piglet lung sections under light microscopy. CCR-2 staining was present in alveolar macrophages, vascular endothelium, and alveolar septa, and on luminal epithelial cells and surfaces of the airways (Fig. 7). CCR-2-staining cells in the interstitium appear to be fibroblasts. These findings are consistent with CCR-2 being expressed by macrophages, endothelial cells, fibroblasts, and the lining epithelial cells of the airways. Vascular and airway smooth muscle cells apparently did not stain.

Intraalveolar macrophages. The intraalveolar macrophage count (mean $\pm \mathrm{SD}$ ) per square millimeter is presented in Table 1. The $\mathrm{O}_{2}$ and $\mathrm{O}_{2}+\mathrm{NO}$-exposed piglets had statistically greater numbers of intraalveolar macrophages than the RA group. No difference was observed in the count between the $\mathrm{RA}+\mathrm{NO}$ and the RA group lungs.

Lung neutrophils. MPO is fairly specific to neutrophils and therefore is an accepted marker for neutrophils (22). Immunohistochemical MPO scores for the respective groups are presented in Table 1 . The scores are significantly higher for the $\mathrm{O}_{2}$ and $\mathrm{O}_{2}+\mathrm{NO}$ groups compared with the RA group.

Also, lung homogenate MPO activity measured biochemically as an index of neutrophil accumulation showed significantly increased neutrophil content in the $\mathrm{O}_{2}$ and $\mathrm{O}_{2}+\mathrm{NO}-$ exposed piglet lungs compared with the RA group (data not 


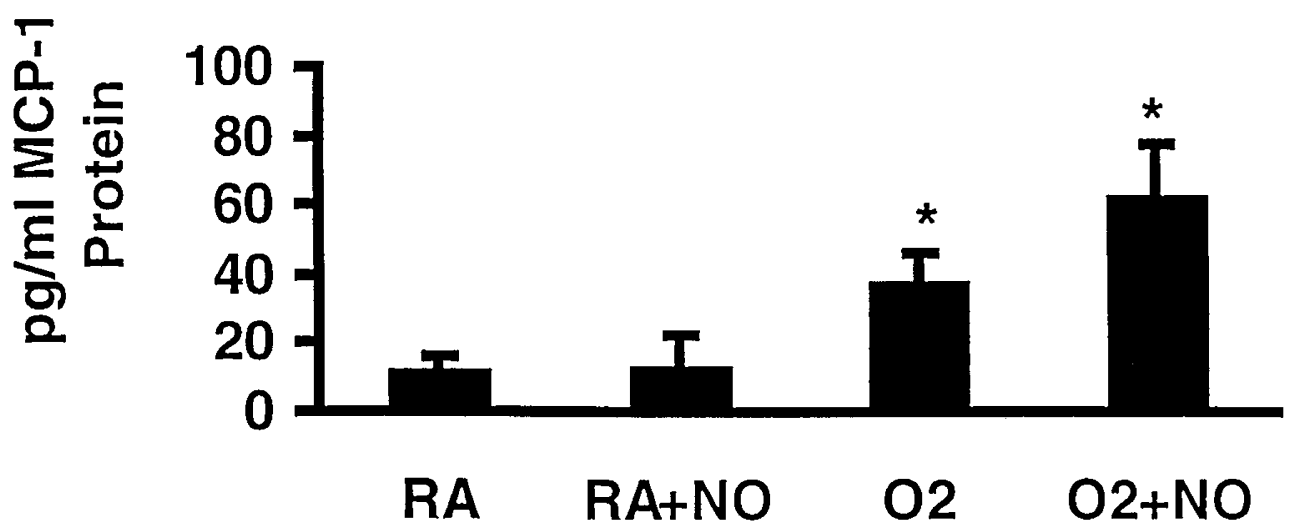

Figure 4. Graph of MCP-1 protein level in lung lavage fluid from the 5-d piglet experiments, expressed in picograms per milliliter. Note the increased MCP-1 protein levels in the $\mathrm{O}_{2}$ and $\mathrm{O}_{2}+\mathrm{NO}$ groups. ${ }^{*} p<0.05$ compared with RA group.

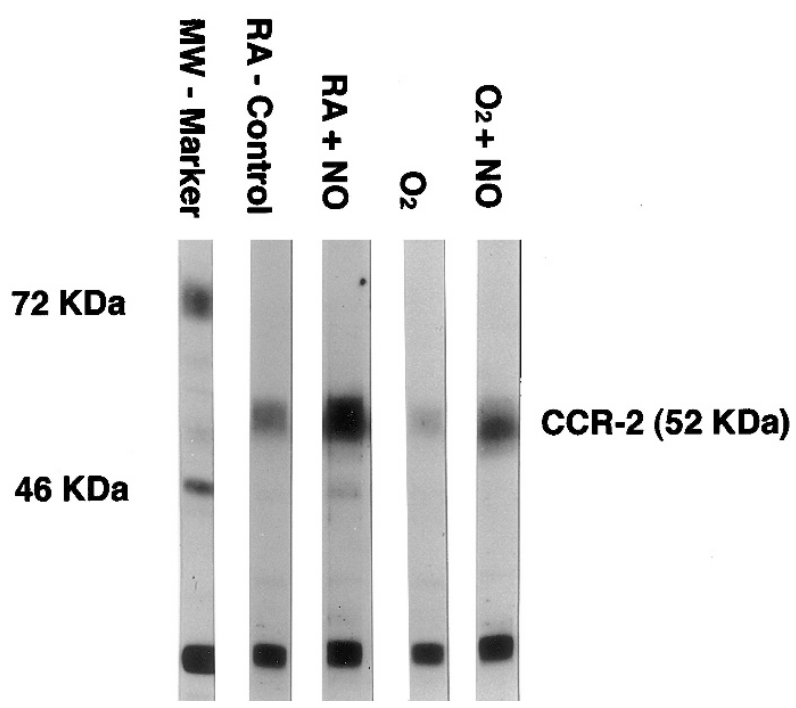

Figure 5. Photograph of the protein bands detected on Western blot for CCR-2 from the piglet lungs. Note that the CCR-2 protein band in the $\mathrm{O}_{2}$ group appears diminished.

shown). The MPO level in the $\mathrm{RA}+\mathrm{NO}$ group piglet lungs was not different from the RA group.

\section{DISCUSSION}

To our knowledge, this is the first report on the effect of inhaled NO with or without hyperoxia on lung MCP-1 and its receptor, CCR-2. We have shown that breathing $\mathrm{O}_{2}$ (hyperoxia) or $\mathrm{O}_{2}+\mathrm{NO}$ for $5 \mathrm{~d}$, but not $\mathrm{NO}$ alone $(\mathrm{RA}+\mathrm{NO})$, increases MCP-1 production and intraalveolar macrophage count in piglet lungs. However, the increase in alveolar macrophage count does not appear to stem from the rise in MCP-1 levels because hyperoxia also caused a reduction in lung CCR-2 abundance. Concurrent exposure to NO during hyperoxic gas breathing mitigated the reduction in lung CCR-2 level caused by hyperoxia. Unlike the hyperoxia-induced changes in its abundance, CCR-2 distribution in the lungs did not change with either study gas or concurrent exposure to both. Twentyfour-hour exposure to either gas alone had no effect on lung MCP-1 or other variables measured in this study and therefore will not be discussed further.

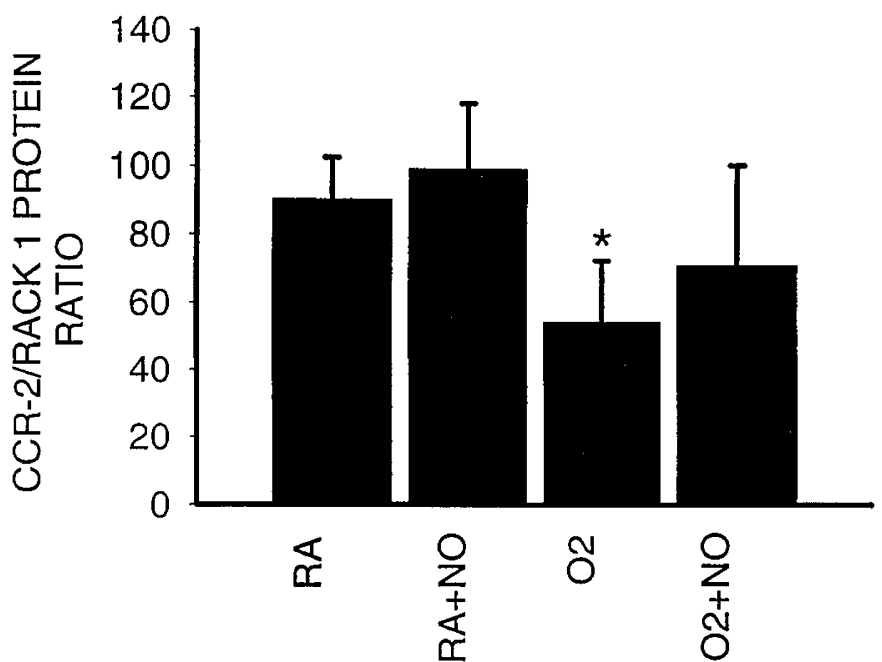

Figure 6. Graph of the mean densitometric values for CCR-2 protein bands obtained on Western blotting of the piglet experimental groups lungs, normalized to that of RACK 1 protein. Note that CCR-2 is decreased in the $\mathrm{O}_{2}$ group. $* p<0.05$ compared with RA group.

In contrast to the lack of existing data for inhaled $\mathrm{NO}$ with or without hyperoxia, there are reports on the effect of reactive oxygen species as well as of hyperoxia on $\mathrm{MCP}-1$ production $(12,13,23)$. There are no data, however, on the effect of hyperoxia on CCR-2 expression. Satriano et al. (12) in cell culture experiments reported that reactive oxygen species activate MCP-1 gene transcription. In a similar experiment, Cooper et al. (13) demonstrated that hyperoxia increases MCP-1 through increased MCP-1 mRNA production and transcript stability. D'Angio et al. $(23,24)$, in their studies of hyperoxia effects, reported significant increases in MCP-1 mRNA transcripts. However, MCP-1 gene translation was not assessed, although arguably it should increase because chemokine production almost always is under transcriptional control. In the present report, we found that hyperoxia increases both MCP-1 mRNA transcripts and protein production.

Although there was no difference in lung MCP-1 mRNA production between the $\mathrm{O}_{2}$ and $\mathrm{O}_{2}+\mathrm{NO}$ piglets, MCP-1 protein was, however, statistically greater in the lavage fluid of $\mathrm{O}_{2}+\mathrm{NO}$ piglets. This discordance between MCP-1 mRNA and protein level could be explained if $\mathrm{NO}$, in the presence of 

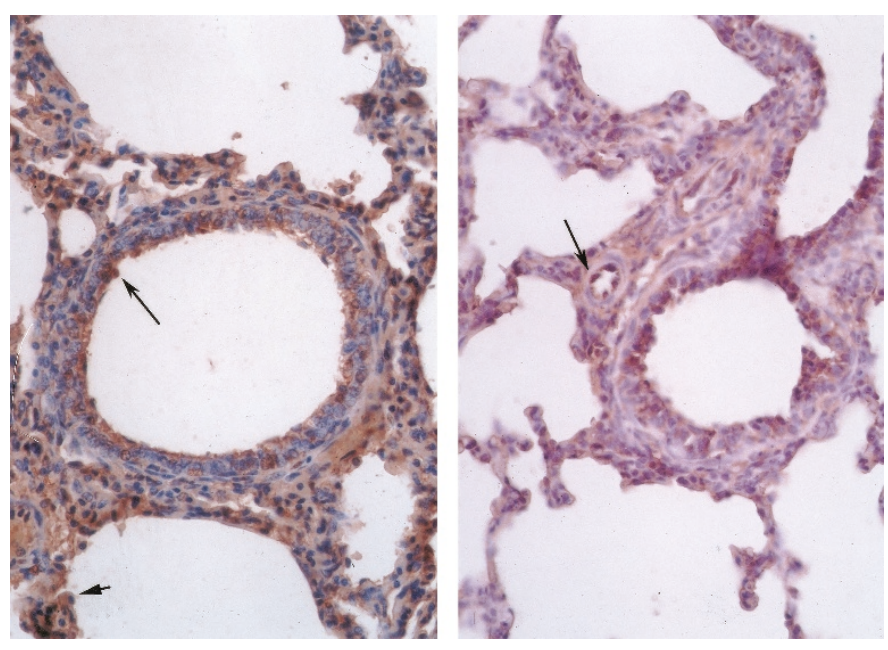

Figure 7. Immunohistochemical staining of $4-\mu \mathrm{m}$ paraffin sections of lung tissue for CCR-2 in the piglet lungs $(\times 400)$. The staining distribution was the same in all piglet groups except that the intensity was less in the $\mathrm{O}_{2}$ group. The medium size bronchiole on the left shows receptor staining of some of the epithelial cells (long arrow on left). The alveolar septa (short arrow on left) are also stained. The terminal bronchiole on the right shows somewhat less epithelial cell receptor staining. Also seen (long arrow on right) is arterial endothelial staining. Alveolar macrophages, vascular endothelium, fibroblasts, and luminal epithelial cells, as well as surfaces of the airways, all stained positive for CCR-2.

Table 1. Lung leukocyte assessment

\begin{tabular}{lcccc}
\hline & $\mathrm{RA}$ & $\mathrm{RA}+\mathrm{NO}$ & $\mathrm{O}_{2}$ & $\mathrm{O}_{2}+\mathrm{NO}$ \\
\hline $\begin{array}{c}\text { Number of alveolar } \\
\text { macrophages } / \mathrm{mm}^{2}\end{array}$ & $0.84 \pm 0.98$ & $20.6 \pm 1.8$ & $4.93 \pm 2.65^{*}$ & $4.86 \pm 3.2 *$ \\
$\begin{array}{c}\text { Lung MPO score } \\
\text { (neutrophils) }\end{array}$ & $1.33 \pm 0.52$ & $1.50 \pm 0.55$ & $3.50 \pm 0.55 *$ & $3.67 \pm 0.52 *$ \\
\hline
\end{tabular}

Values are mean $\pm \mathrm{SD}$.

$* p<0.05$, significant difference compared with RA.

hyperoxia, increased MCP-1 gene translation or posttranslation while hyperoxia increased transcription alone. Evidence for the existence of such a mechanism includes the report by Bellocq et al. (25) that reactive nitrogen intermediaries increase transforming growth factor- $\beta 1$ release from human alveolar epithelial cells through translational or posttranslational modulation, whereas reactive oxygen species had an up-regulatory effect on transcription. Indeed, high levels of both reactive nitrogen intermediaries and oxygen species are generated during concurrent exposure to NO and hyperoxia $(17,18)$.

Western blot analysis revealed a significant reduction in CCR-2 protein expression in the lungs of $\mathrm{O}_{2}$-exposed piglets compared with the RA group. The CCR-2 abundance in the $\mathrm{O}_{2}+\mathrm{NO}$ group did not differ from that of the RA group. Thus the results show that exposure to hyperoxia decreases rather than increases CCR-2 protein expression. Also, concurrent exposure to $\mathrm{NO}$ attenuates the decrement effect of hyperoxia on lung CCR-2 protein abundance. The "protective" effect of $\mathrm{NO}$ in this instance may be from its acting as a free radical scavenger (26-29).

As expected, we found an abundance of neutrophils and intraalveolar macrophages in the $\mathrm{O}_{2}$ and $\mathrm{O}_{2}+\mathrm{NO}$ piglet lungs relative to the RA group. Like MCP-1, IL-8 mRNA was significantly elevated in this same group of piglets, consistent with a role for this chemokine in the lung neutrophil influx. Others have shown a strong correlation between IL-8 levels and lung neutrophil accumulation during hyperoxia (11, 23, 30). Blockage of IL-8, or of its major receptors CXCR-1 and CXCR-2, which are up-regulated during hyperoxia, decreases lung neutrophil accumulation $(30,31)$. Thus IL-8 has key roles in lung neutrophil dynamics during hyperoxia exposure.

In contrast, the participation of MCP-1 in lung macrophage accumulation during hyperoxia has not been examined to the same extent. Previous work has established that MCP-1 has chemoattractant properties and that its level is increased by hyperoxia exposure $(5,11,24)$. The present study found both an increase in MCP-1 production and in intraalveolar macrophages, but a decrease in CCR-2 in the lungs of the $\mathrm{O}_{2}$-exposed piglets. These findings would argue against a role for MCP-1 as being the driving force for lung macrophage recruitment during hyperoxia. D'Angio et al. (11), in a study of newborn rabbits exposed to hyperoxia, observed that alveolar macrophage recruitment did not correlate with MCP-1 levels. The data obtained from young piglets in the present study are consistent with their observation but also suggest that the decrease in CCR-2 associated with hyperoxia may have limited participation by MCP-1 in the alveolar macrophage recruitment.

Although MCP-1 can bind to the CCR-1 and CCR-4 receptors, its affinity for these receptors is so weak that only minimal signal transduction is believed to occur through the former and none through the later (10). These receptors therefore cannot substantially substitute for significant reductions in CCR-2 level. Alternative substances that could have promoted macrophage recruitment include the chemokines macrophage inflammatory protein-1 alpha and macrophage inflammatory protein-1 beta, both of which share similar chemoattractant properties as MCP-1 $(32,33)$.

Several stimuli, including cytokines, infectious agents, endotoxin, and lipopolysaccharide, have been shown in in vitro studies to decrease CCR-2 receptor expression with a concomitant reduction in monocyte trafficking (34-36). However, multiple competing mechanisms are usually operative in a whole animal model; therefore the results obtained from in vitro studies do not always reflect events in the intact animal. Mice made deficient in CCR-2 by gene knockout show decreased firm leukocyte adhesion to vascular endothelium and reduced extravasation in response to MCP-1 (37). Macrophage influx into the peritoneal cavity and granuloma formation in the liver in response to thioglycollate and beta-glucan injection, respectively, is also impaired in these mice compared with wild-type mice (37). However, alveolar macrophage trafficking, especially in response to hyperoxia, has not been examined in this model.

There appear to be multiple mechanisms involved in pulmonary transmicrovascular migration of leukocytes into the lungs and they are not fully understood, unlike that of the systemic circulation (38). The existence of both ligandreceptor-dependent and -independent leukocyte emigration pathways that are also stimulus specific has been demonstrated for the pulmonary circulation (39). One such pathway is emigration on the basis of stimuli-induced deformation of leuko- 
cyte cell wall. Thus, a physical change in the leukocyte rather than ligand-receptor interaction directs leukocyte traffic into the lung. This pathway may explain the increase in lung alveolar macrophage trafficking despite a hyperoxia-induced decrease in lung CCR-2. Keeney et al. (40) have shown that blockade of neutrophil CD18 receptors with MAb did not decrease lung neutrophil recruitment during exposure to hyperoxia.

CCR-2 staining distribution in the lungs showed it is present in alveolar macrophages, vascular intima, and alveolar septa, and on luminal epithelial cells and surfaces of airways. These findings are consistent with CCR-2 being expressed by macrophages, endothelial cells, fibroblasts, and the lining epithelial cells of larger and intermediate airways. CCR-2 was once thought to be exclusively expressed by monocytes and macrophages but has since been demonstrated in other cell types. Our data appear to be the first describing CCR-2 distribution in the lungs. The staining of luminal epithelial cells and surfaces of the airways would suggest they express CCR-2.

The results from the current study may be important for several reasons. First, we described CCR-2 distribution in the lungs and the depressant effect of hyperoxia on CCR-2 abundance. This may have potential implications for lung repair after injury, because MCP-1 acting through CCR-2 participates in angiogenesis and in wound repair $(6,8,41)$. Next, we showed that combined exposure to hyperoxia and NO did not exacerbate the depressant effect of hyperoxia on CCR-2 but may actually be protective. This may suggest a potential beneficial role for NO in minimizing the injurious effect of hyperoxia on angiogenesis and repair. This possibility lends support to testing NO as a prophylaxis for chronic lung disease of prematurity. Finally, data from this study suggest that strategies targeting CCR-2 blockade to decrease lung macrophage activation and injury are unlikely to be successful, but instead may pose potential problems for angiogenesis and repair.

The limitations of the present study include the fact that only a single and relatively high dose of $\mathrm{NO}$ was studied, and that only two times, d 1 and 5, were studied. The absence of the potentially confounding effects of mechanical ventilation as would be used in the clinical setting could be viewed as either a limitation or a clarifying factor. Nevertheless, useful insights are gained regarding the interaction of $\mathrm{O}_{2}$ and $\mathrm{NO}$ during combined use to influence MCP-1 and CCR-2 level.

In summary, this study found that hyperoxia has a paradoxical effect of increasing lung MCP-1 production but decreasing CCR-2 abundance in young piglet lungs. Lung leukocyte dynamics in hyperoxia, therefore, may be independent of changes in MCP-1 and its receptor level. Concurrent exposure to inhaled NO may mitigate the decremental effect of hyperoxia on lung CCR-2 abundance. Unlike the effect of hyperoxia, administration of NO alone did not affect lung MCP-1 production or CCR-2 abundance. We speculate that hyperoxia decrement in lung CCR-2 contributes to the microvascular injury and altered repair characteristic of hyperoxia lung injury. Further studies are warranted to specifically evaluate the role of the increased MCP-1 level in hyperoxia lung injury.
Acknowledgment. The authors thank Mary S. Bailey for her administrative assistance and patience in preparation of this manuscript.

\section{REFERENCES}

1. Fox RB, Hodal JR, Brown DM, Repine JE 1981 Pulmonary inflammation due to oxygen toxicity: involvement of chemotactic factors and polymorphonuclear leukocytes. Am Rev Respir Dis 123:521-525

2. Frank L, Massaro D 1980 Oxygen toxicity. Am J Med 69:117-126

3. Sibille Y, Reynolds HY 1990 Macrophages and polymorphonuclear neutrophils in lung disease and injury. Am Rev Respir Dis 141:471-501

4. Taub DD 1996 Chemokine-leukocyte interactions: the voodoo that they do so well. Cytokine Growth Factor Rev 7:355-376

5. Leonard EH, Yoshimura T 1990 Human monocyte chemoattractant protein-1 (MCP1). Immunol Today 11:97-101

6. Nasreen N, Mohammed KA, Galffy G, Ward MJ, Antony VB 2000 MCP-1 in pleural injury: CCR-2 mediates haptotaxis of pleural mesothelial cells. Am J Physiol 278:L591-L598

7. Hogaboam CM, Bone-Larson CL, Lipinski S, Lukacs NW, Chensue SW, Strieter RM, Kunkel SL 1999 Differential monocyte chemoattractant protein-1 and chemokine receptor 2 expression by murine lung fibroblasts derived from Th1- and Th2-type pulmonary granuloma models. J Immunol 163:2193-2201

8. Weber KS, Nelson PJ, Grone HJ, Weber C 1999 Expression of CCR-2 by endothelial cells: implications for MCP-1 mediated wound injury repair and in vivo inflammatory activation of endothelium. Arterioscler Thromb Vasc Biol 19:2085-2093

9. Hayes IM, Jorda NJ, Towers S, Smith G, Paterson JR, Earnshaw JJ, Roach AG, Westwick J, Williams RJ 1998 Human vascular smooth muscle cells express receptors for CC chemokines. Arterioscler Thromb Vasc Biol 18:397-403

10. Charo IF, Myers SJ, Herman A, Franti C, Connolly AJ, Coughlin SR 1994 Molecular cloning and functional expression of two monocyte chemoattractant protein 1 receptors reveals alternative splicing of the carboxyl-terminal tails. Proc Natl Acad Sci USA 91:2752-2756

11. D'Angio CT, LoMonaco MB, Chaudhry SA, Paxhia A, Ryan RM 1999 Discordant pulmonary proinflammatory cytokine expression during acute hyperoxia in the newborn rabbit. Exp Lung Res 25:443-465

12. Satriano JA, Shuldiner M, Kazuhiko H, Xing Y, Shan Z, Schlondorff D 1993 Oxygen radicals as second messengers for expression of the monocyte chemoattractant protein, JE/MCP-1, and the monocyte colony-stimulating factor, CSF-1, in response to tumor necrosis factor- $\alpha$ and immunoglobulin $\mathrm{G}$ : evidence for involvement of reduced nicotinamide adenine dinucleotide phosphate (NADPH)-dependent oxidase. J Clin Invest 92:1564-1571

13. Cooper Jr JAD, Fuller JM, McMinn KM, Culbreth RR 1998 Modulation of monocyte chemotactic protein-1 production by hyperoxia: importance of RNA stability in control of cytokine production. Am J Respir Cell Mol Biol 18:521-525

14. Chollet-Martin S, Gatecel C, Kermarrec N, Gougerot-Pocidalo MA, Payen DM 1996 Alveolar neutrophil functions and cytokine levels in patients with the adult respiratory distress syndrome during nitric oxide inhalation. Am J Respir Crit Care Med 153:985-990

15. Roberts JD, Polaner DM, Land P, Zapol WM 1992 Inhaled nitric oxide in persistent pulmonary hypertension of the newborn. Lancet 340:818-819

16. Kinsella JP, Neish SR, Ivy DD, Shaffer E, Abman SH 1993 Clinical response to prolonged treatment of persistent pulmonary hypertension of the newborn with low doses of inhaled nitric oxide. J Pediatr 123:103-108

17. Stamler JS, Singel DJ, Loscalzo J 1992 Biochemistry of nitric oxide and its redoxactivated forms. Science 258:1898-1902

18. Radi R, Beckman JS, Bush KM, Freeman BA 1991 Peroxynitrite oxidation of sulfhydryls: the cytotoxic potential of superoxide and nitric oxide. J Biol Chem 266:4244-4250

19. Beckman JS, Beckman TW, Chen J, Marshall PA, Freeman BA 1990 Apparent hydroxyl radical formation by peroxynitrite: implications for endothelial injury from nitric oxide and superoxide. Proc Natl Acad Sci USA 87:1620-1624

20. Ekekezie II, Thibeault DW, Zwick DL, Rezaiekhaligh MH, Mabry SM, Morgan RE, Norberg M, Truog WE 2000 Independent and combined effects of prolonged inhaled nitric oxide and oxygen on lung inflammation in newborn piglets. Biol Neonate 77:37-44

21. Preobrazhensky AA, Dragon S, Kawano T, Gavrilin MA, Gulina IV, Chakravarty L, Kolattukudy PE 2000 Monocyte chemotactic protein-1 receptor CCR2B is a glycoprotein that has tyrosine sulfation in a conserved extracellular N-terminal region. J Immunol 165:5295-5303

22. Goldblum SE, Wu KM, Jay M 1985 Lung myeloperoxidase as a measure of pulmonary leukostasis in rabbits. J Appl Physiol 59:1978-1985

23. D'Angio CT, Johnston CJ, Wright TW, Reed CK, Finkelstein JN 1998 Chemokine mRNA alterations in newborn and adult mouse lung during acute hyperoxia. Exp Lung Res 24:685-702

24. D'Angio CT, Sinkin RA, LoMonaco MB, Finkelstein JN 1995 Interleukin-8 and monocyte chemoattractant protein-1 mRNAs in oxygen-injured rabbit lung. Am J Physiol 268:L826-L831

25. Bellocq A, Azoulay E, Marullo S, Flahault A, Fouqueray B, Philippe C, Cadranel J, Baud L 1999 Reactive oxygen and nitrogen intermediates increase transforming growth factor- $\beta 1$ release from human epithelial alveolar cells through two different mechanisms. Am J Respir Cell Mol Biol 21:128-136

26. Gutierrez HH, Nieves B, Chumley P, Rivera A, Freeman BA 1996 Nitric oxide regulation of superoxide-dependent lung injury: oxidant-protective actions of endo- 
genously produced and exogenously administered nitric oxide. Free Radic Biol Med 21:43-52

27. Turanlahti P, Lassus A 2000 Nitric oxide and hyperoxia in oxidative lung injury. Acta Paediatr 89:966-970

28. Issa A, Lappalainen U, Kleinman M, Bry K, Hallman M 1999 Inhaled nitric oxide decreases hyperoxia-induced surfactant abnormality in preterm rabbits. Pediatr Res 45:247-254

29. Kinsella JP, Walsh WF, Bose CL, Gerstmann DR, Labella JJ, Sardesai S, WalshSukys MC, McCaffrey MJ, Cornfield DN, Bhutani VK, Cutter GR, Baier M, Abman SH 1999 Inhaled nitric oxide in premature neonates with severe hypoxaemic respiratory failure: a randomised controlled trial. Lancet 354:1061-1065

30. Strieter RM, Kunkel SL 1994 Acute lung injury: the role of cytokines in the elicitation of neutrophils. J Invest Med 42:640-651

31. Deng H, Mason SN, Auten Jr RL 2000 Lung inflammation in hyperoxia can be prevented by anti-chemokine treatment in newborn rats. Am J Respir Crit Care Med 162:2316-2323

32. Smith RE 1996 Chemotactic cytokines mediate leukocyte recruitment in fibrotic lung disease. Biol Signals 5:223-231

33. Driscoll KE 1994 Macrophage inflammatory proteins: biology and role in pulmonary inflammation. Exp Lung Res 20:473-490

34. Sica A, Saccani A, Borsatti A, Power CA, Wells TNC, Luini W, Polentarutti N, Sozzani S, Mantovani A 1997 Bacterial lipopolysaccharide rapidly inhibits expression of C-C chemokine receptors in human monocytes. J Exp Med 185:969-974
35. Penton-Rol G, Polentarutti N, Luini W, Borsatti A, Mancinelli R, Sica A, Sozzani S, Mantovani A 1998 Selective inhibition of expression of the chemokine receptor CCR-2 in human monocytes by IFN- $\gamma$. J Immunol 160:3869-3873

36. Zhou Y, Yang Y, Warr G, Bravo R 1999 LPS down-regulates the expression of chemokine receptor CCR-2 in mice and abolishes macrophage infiltration in acute inflammation. J Leukoc Biol 65:265-269

37. Kuziel WA, Morgan SJ, Dawson TC, Griffin S, Smithies O, Ley K, Maeda N 1977 Severe reduction in leukocyte adhesion and monocyte extravasation in mice deficient in CC chemokine receptor 2. Proc Natl Acad Sci USA 94:12053-12058

38. DeLisser HM, Albelda SM 1998 The function of cell adhesion molecules in lung inflammation: more questions than answers. Am J Respir Cell Mol Biol 19:533536

39. Doerschuk CM, Winn RK, Coxson HO, Harlan JM 1990 CD18-dependent andindependent mechanisms of neutrophil emigration in the pulmonary and systemic microcirculation of rabbits. J Immunol 144:2327-2333

40. Keeney SE, Mathews MJ, Haque AK, Rudloff HE, Schmalstieg FC 1994 Oxygeninduced lung injury in the guinea pig proceeds through CD18-independent mechanisms. Am J Respir Crit Care Med 149:311-319

41. Salcedo R, Ponce ML, Young HA, Wasserman K, Ward JM, Kleinman HK, Oppenheim JJ, Murphy WJ 2000 Human endothelial cells express CCR-2 and respond to $\mathrm{MCP}-1$ : direct role of $\mathrm{MCP}-1$ in angiogenesis and tumor progression. Blood 96:34-40 